\title{
ИНСТИТУЦИОНАЛЬНОЕ ДОВЕРИЕ И ЕГО РОЛЬ В ОБЕСПЕЧЕНИИ ЭКОНОМИЧЕСКОЙ БЕЗОПАСНОСТИ СТРАНЫ
}

\author{
(c) 2019 Коновалова Мария Евгеньевна \\ доктор экономических наук, заведующий кафедрой экономической теории \\ Самарский государственный экономический университет, Россия, Самара \\ E-mail:mkonoval@mail.ru \\ (c) 2019 Кузьмина Ольга Юрьевна \\ кандидат экономических наук, доцент кафедры экономической теории \\ Самарский государственный экономический университет, Россия, Самара \\ E-mail: pisakina83@yandex.ru \\ (c) 2019 Суриков Константин Юрьевич \\ кандидат экономических наук \\ E-mail: sourikov.k@mail.ru
}

В статье рассматривается роль внеэкономических институциональных факторов, в том числе доверия, детерминирующих формирование основ экономической безопасности страны. Доказано, что рост институционального доверия обеспечивает снижение трансакционных и трансформационных издержек, что способствует созданию условий для повышения темпов экономического роста, обусловливая при этом рост конкурентоспособности отечественной экономики, делая ее более устойчивой к внешним шокам.

Ключевые слова: институциональное доверие, финансовые институты, экономическая безопасность, предпринимательство, конкурентоспособность, экономический рост

Последний ряд лет развитие нашей страны происходит в достаточно сложных геополитических и экономических условиях. Нарастание санкционного давления со стороны стран Запада обусловливает повышение значимости проблем, связанных с обеспечением экономической безопасности страны. Традиционно экономическая безопасность рассматривается как важнейшая системообразующая характеристика воспроизводственного процесса, отражающая способность социально-экономической системы противостоять внешним угрозам с помощью эффективных методов их отражения, обеспечивая при этом стабильность ее развития. Следует заметить, что в научной литературе категория «экономическая безопасность» [11] относительно нова, в текущий момент происходит ее теоретическое осмысление, причем, не только с точки зрения экономической науки, но и ряда других, таких как философия, психология, социология и т.п. Это говорит о том, что рассматриваемое явление обладает определенной полиморфностью, что подчас затрудняет задачу исследователей в процессе выявления сущности и содержания изучаемой категории.
Наше исследование посвящено изучению институциональных аспектов, в том числе такого специфического квазиинститута как доверие в процессе обеспечения экономической безопасности страны [1]. В современных условиях вовлечение доверительных отношений в воспроизводственный процесс уже не вызывает сомнения, поскольку наблюдается все большее влияние поведенческих особенностей хозяйствующих акторов на ход реальных процессов, характеризующих экономическое бытие. Среди научного сообщества можно выделить ряд авторов, активно исследующих в своих трудах роль внеэкономических факторов в воспроизводственном процессе, в том числе феномена доверия. Это, несомненно, Ф. Фукуяма - основоположник теории доверия как ключевого экономического фактора, сюда же следует отнести К. Эрроу, Дж. Ходжсона, А. Селишмена, А. Штомке, Я. Конаи, Д. Скотта и многих других. Нельзя не отметить и роль австрийской школы (Л. фон. Мизес, Ф. фон Хайек) в исследовании поведения индивидов в предпринимательской деятельности, которая возможна только в условиях высокого уровня персонифицированного доверия $[1,2,10]$. 
Рост значимости внеэкономических факторов обусловил всплеск интереса к их теоретическому осмыслению и среди российских ученых. появились труды, посвященные данной проблематики таких экономистов как А. Олейник, В. Радаев, В. Дементьев, А. Ляско, В. Сухих, С. Важенин и ряда других. Главный вывод, который можно сделать на основании изложенных положений в трудах ученых-экономистов состоит в том, что экономика не является изолированным пространством, в котором люди собираются вместе лишь для того, чтобы удовлетворить свои частные эгоистические потребности, а затем вернуться в свою обыденную жизнь. На самом деле экономика представляет собой базовую и постоянно изменяющуюся сферу человеческой жизнедеятельности и общения, и в которой поведение одних ее членов непосредственным образом сказывается на решениях, принимаемых другими участниками системы.

Институциональная теория, а, в частности, ее методологический инструментарий дает возможность исследовать воздействие внеэкономических факторов на реальные хозяйственные процессы. Препарируя доверие посредством методологии институционального подхода [3], мы пришли к выводу, что его нельзя считать институтом в традиционном понимании данной категории. В связи с этим мы по-прежнему сомневаемся в использовании «института» доверия как ключевого элемента социального и институционального капитала [5]. Для того, чтобы отнести то или иное явление к категории института необходимо его четкая спецификация относительно базовых признаков института, к которым в экономической литературе относят следующие его свойства: организация, ограничение и упорядочивание непрерывного взаимодействия субъектов в процессе воспроизводства различных отношений.; реализация основного функционального назначения, связанного с соответствием поставленным целям развития социально-экономической системы; наличие ограничителей в процессе функционирования в виде формальных и неформальных норм и правил, а также обладание механизмом принуждения, необходимых в качестве контроля за соблюдением этих норм. На наш взгляд, доверие как явление нельзя в полной мере отнести к категории института, так как механизм инфорсмента присутствует здесь только в снятом виде, не имея четко выраженных санкций за нарушения норм доверительного отношения. Если привести аналогию с существующими неформальными институтами такими, например, как традиции, обычаи, мораль и др. то нарушение вышеназванных норм имеет достаточно четко сформированный аппарат принуждения в виде отчуждения, исключения, астракизма и т.п. санкций [6]. Следовательно, доверие можно классифицировать как квазиинститут неформального типа, который тем не менее играет существенную роль в развитии экономической системы, и в том числе формировании условий для экономической безопасности страны. Говоря о значении доверительных отношений в процессе общественного воспроизводства следует выделить их формы, в которых возможно проявление этого чувства. Так, выделяют минимальный (наноуровень), микроуровень и макроуровень. По степени персонификации можно отметить персонифицированное, деперсонифицированное, обобщенное (институциональное) доверие. Под институциональным доверием понимается опосредованная человеческим поведением форма доверия к конкретным нормам, правилам (институтам). Современная социально-экономическая система насквозь пронизана нормами, правилами и предписаниями, следовательно от того насколько четко они будут соблюдаться хозяйствующими акторами зависит ее транспарентность, управляемость и в конечном счете эффективность [9].

Высокий уровень институционального доверия обеспечивает уменьшение неопределенности, снижение асимметрии информации, трансакционных издержек, что способствует формированию условий для качественного экономического роста. Доверие к институтам определяется тем, насколько сами эти институты отвечают ожиданиям субъектов, то есть способны реализовывать принципы экономической эффективности и социальной справедливости.

Как полагает ряд экспертов укрепление доверия возможно только в случае реального подтверждения того, что существующие институты работоспособны, особенно в условиях динамических изменений, и удовлетворяют потребности основной массы населения.

Одним из видов институционального доверия является доверие к монетарным институтам [8]. Доверительные отношения являются неотъемлемой частью любых операций, связанных с денежным обращением. Деньги пред- 
ставляют собой фундамент функционирования любой экономической системы, основанной на использовании обмена и кредита, следовательно важное значение будет иметь доверие со стороны хозяйствующих субъектов к национальной денежной единице, что в конечно счете создаст условия для стабильности системы денежного обращения и всего финансового сектора. пи низком уровне институционального доверия денежное обращение вообще может быть под угрозой, так как участники монетарного оборота будут сомневаться в ликвидности денежных знаков, что создаст препятствие для осуществления воспроизводственного процесса и сделает уязвимой национальную экономику в целом. Нарушения функционирования системы денежного обращения неизбежно приведет к сбоям в работе предприятий, организаций, государственных органов, нарушая при этом базовые принципы экономической безопасности.

Как полагает ряд ученых современная монетарная система представляет собой разветвленную сеть доверительных отношений, причем построенную в соответствии не только с горизонтальным, но и вертикальным типом координации хозяйствующих субъектов. Современная структура современных денежных отношений выстраивается по принципу доверия не только в наиболее надежным, а это в основном государственные институты, но и исходя из возможности эмиссии наиболее ликвидных денежных форм.

Квазиденьги всегда превращаются в ликвидные финансовые обязательства, а в последующем и в наличные денежные знаки, что происходит при непосредственном участии банковской системы и государства. Деление эмитентов на основании степени ликвидности выпускаемых ими активов отражает и иерархическую упорядоченность финансовых институтов по степени деперсонифицированного доверия хозяйствующих субъектов, а, следовательно, не только надежность, но и ликвидность выпускаемых активов является базовым критерием выстраивания вертикальных связей в финансовой системе [7].

Можно отметить, что пирамида доверительных отношений к монетарным институтам формируется в полном соответствии со средствами институциональной защиты.

Современная монетарная система претерпевает существенные изменения, связанные с переходом от классических наличных и без- наличных форм денег к их электронному виду. Всевозможные криптовалюты лишь частично обладают денежных функционалом. Их можно идентифицировать как квазиденьги только когда они используются как средства расчеты и платежей в системе электронной коммерции. Подобные денежные характеристики появляются у криптовалют не так часто, в большинстве стран мира, в том числе и в России, криптовалюты представляют собой денежный суррогат, то есть актив, который не может напрямую участвовать в расчетных и платежных операциях. Криптовалюты это не столько деньги, сколько спекулятивная составляющая финансовых отношений [8].

Рынок криптовалют не вписывается в классическую схему иерархию доверительных отношений к деньгам (доверие к деньгам $\rightarrow$ доверие к банкам $\rightarrow$ доверие к государству), образуя самостоятельную область фидуциарных связей. В процессе купли-продажи криптовалюты хозяйствующий субъект доверяет не отдельным лицам или институтам, а самой системе, то есть технологическому алгоритму эмиссии криптознаков.

Экономическая безопасность процедуры майнинга и обращения криптовалют по мнению многих авторов позиционируется как стопроцентная. Однако, как нам видится это не совсем. Во-первых, сам алгоритм эмиссии денежных суррогатов, выстраиваемый с использованием технологии блокчейн, может обладать определенными ограничениями. Концентрация больших энергетических мощностей в руках отдельного участника крипторынка позволит ему выстраивать более длинные цепочки «блоков», тем самым обеспечивая возможность искажения механизма ценообразования и эмиссии криптовалюты. На данном этапе уже известны факты, когда процедуры майнинга контролируются большими пулами, с которыми мелкими добытчики денежных суррогатов делятся своими ресурсами. Сеть концентрируется вокруг операторов крупных дата-центров, в основном расположенных в южных провинциях Китая, что свидетельствует о процессе монополизации криптовалютного рынка.

Кроме того, ограничение есть и на объем эмиссии, что говорит о невозможности включения данного рынка в реальный воспроизводственный процесс. Фиксированный объем эмиссии криптовалюты приводит к удлинению 
блоков, что замедляет скорость его распространения по сети и увеличивает риск разделения, то возрастает угроза несанкционированных действий.

Во-вторых, много вопросов вызывает обращение криптовалюты. Биржи, осуществляющие процесс конвертации криптоденег в фиатные активы, находится в собственности конкретных участников рынка криптовалюты. Государство практически не участвует в регулировании их деятельности, что вызывает риск потери активов в связи с недобросовестностью владельца информационной платформы, который не застрахован также и от банкротства.

Функционирование рынка криптовалюты ставит проблему экономической безопасности не только для отдельно взятого хозяйствующего субъекта, но и для экономики страны в целом.
Бесконтрольное увеличение числа операций с криптоденьгами приводит к экспансии теневого сектора, росту уровня криминализации финансовых потоков, ущемлению прав инвесторов, и к снижению эффективности социально-экономической системы в целом.

Решение проблемы экономической безопасности в финансовом секторе в настоящее время представляется наиболее актуальным. Только при создании благоприятных условий хозяйствования, предполагающих не только сохранение и защиту имеющихся формальных и неформальных институтов [4], но их постоянное воспроизводство на новом качественном уровне можно говорить об устойчивых темпах экономического роста, о возможности противостояния внешних угрозам, повышении качества жизни граждан.

\section{Библиографический список}

1. Белянин А, Зинченко В. Доверие в экономике и общественной жизни. Москва. 2010. С.4.

2. ощегулова И. Денежная теория и институты // Вестн. УГАТУ. Экономика. 2009. Т.12, № 3(32). С. $18-25$.

3. Михайлов А.М. Институциональные формы реализации интересов собственников факторов производства. // Экономические науки. 2007. № 35. С. 71-75.

4. Михайлов А.М., Белова Л.В. Формальные и неформальные институты в банковской сфере // Вопросы экономики и права. 2015. № 88. С. 48-71.

5. Михайлов А.М., Пронина Е.Ю. Экономическая природа институционального капитала и его взаимосвязь с человеческим капиталом. // Вестник Самарского государственного экономического университета. 2013. № 5 (103). С. 85-89.

6. Суриков К.Ю., Коновалова М.Е. Институциональное доверие к деньгам: вопросы теории и практики. Самара, 2016. С. 34-35.

7. Суриков К.Ю., Коновалова М.Е., Кузьмина О.Ю. Институциональное доверие и его роль в процессе развития денежно-кредитной сферы // Вестник Самарского государственного экономического университета. 2016. № 11 (145). С. 5-10.

8. Суриков К.Ю., Коновалова М.Е. Особенности трансформации системы денежного обращения на современном этапе развития // Вестник Самарского государственного экономического университета. 2017. № 10 (156). С. 82-86.

9. Суриков К.Ю. Фактор доверия в эволюции денег // Вестник Самарского государственного экономического университета. 2015. № 4 (126). С. 6-14.

10. Фукуяма Ф. Доверие. Социальные добродетели и путь к процветанию. Москва, 2004. С. 13-17.

11. Якшина И.С. Современные теоретические подходы к содержанию категории экономической безопасности субъектов экономической деятельности // Гуманитарные научные исследования 2013. № 10 (26). С. 3-5. 